\title{
An Agronomic and Profitability Study on Rice Production: A Case of Jalgaon Village of Comilla District, Bangladesh
}

\author{
Rozina Yeasmin Lucky ${ }^{1, ~ *, ~ J a h a n g i r ~ K a b i r ~}{ }^{2}$, Golam Rabbani ${ }^{1}$, Abu Bakr Siddique ${ }^{2}$, \\ Emran Hossain ${ }^{2}$ \\ ${ }^{1}$ Department of Economics, Hajee Mohammad Danesh Science and Technology University, Dinajpur, Bangladesh \\ ${ }^{2}$ Bangladesh Rice Research Institute, Gazipur, Bangladesh \\ Email address: \\ ryeasminluckyhstu@gmail.com(R.Y.Lucky),jkabirbrri@yahoo.com(J.Kabir), grabbanihstu@yahoo.com(G. Rabbani) \\ ${ }^{*}$ Corresponding author
}

\section{To cite this article:}

Rozina Yeasmin Lucky, Jahangir Kabir, Golam Rabbani, Abu Bakr Siddique, Emran Hossain. An Agronomic and Profitability Study on Rice Production: A Case of Jalgaon Village of Comilla District, Bangladesh. International Journal of Agricultural Economics.

Vol. 3, No. 1, 2018, pp. 14-22. doi: 10.11648/j.ijae.20180301.13

Received: January 15, 2018; Accepted: February 24, 2018; Published: March 26, 2018

\begin{abstract}
Performance of rice crops in farmers' fields largely lower than varietal potential. Besides, profitability is an important aspect of production decision for the semi-subsistence farming system in Bangladesh. Therefore, this study was conducted evaluate crops management practice and performance of rice in different seasons. Farmers' group discussion with key informant farmers was conducted for collecting and validating the data using a semi-structured questionnaire. Adoption of modern rice varieties was high in the village. Rice is planted delay in all the seasons because of three crops (rice-rice-rice) rice based cropping patterns in the village. Farmers mainly relied on household seeds (owned stored and purchase from neighboring farmers) in Aus and Aman seasons while the dealer supplied seed is the prime seed source in Boro season. The seed rates were largely higher than recommendation rates. Farmers' fertilizers management is highly inconsistent with recommendation practice. Both manual and chemical methods are used for controlling weeds. Chemical method is mainly practiced for controlling insects and diseases of crops. Paddle and power thresher is used for threshing rice. Boro rice gave Boro rice gave higher yield $(4.94 \mathrm{t} / \mathrm{ha})$ followed by T. Aman $(3.29 \mathrm{t} / \mathrm{ha})$ and Aus $(3.09 \mathrm{t} / \mathrm{ha})$ due to better cropping environment, good management practices, higher inputs and usages of better genotypes. The performance of rice in the three seasons showed large yield gap. T. Aman gave higher gross margin (BDT 22,015/ha) followed by Boro (BDT 16,468/ha) and Aus (BDT 9,414/ha) because of higher price and lower production cost. Participation of women in the intercultural operations of crops and their role sin decision making about farming was a few. Nevertheless, they intensively participate in post-harvest processing of crops and other household activates and decisions. In short, despite a large yield gap, rice production is profitable in the three seasons at survey year's price. The poorer access to extension service, good quality seed, phosphorous fertilizers, pesticides and power supply were identified as barrier to achieve potential performance of rice cultivars and expected level of returns. Thus, policy supports for increasing access to extension supports and quality inputs may reduce yield gap and enhance productivity and profitability of rice crops largely.
\end{abstract}

Keywords: Agronomic, Profitability, Rice Production, Bangladesh

\section{Introduction}

Bangladesh is a small $(147,570$ sq. km2) and densely populated (976 persons $/ \mathrm{km} 2$ ) agriculture base country. High population growth $(2.18 \%)$ with low growth in agricultural productivity adversely affects the living standard of 142.3 million people in the country in $2011[1,2]$. The contribution of agriculture in gross domestic product (GDP) decreased to $11.33 \%$ in 2015/16 from $21.84 \%$ in $2005-06$ [3, 4]. However, still agriculture is mainstay of economy, over $80 \%$ of rural population directly and indirectly depends on agriculture for livelihoods [5]. Besides, on the average $45 \%$ of total people were employed in agriculture [5]. The country is nearly selfsufficient in staple food rice production but still a large 
deficit in production of wheat, pulses, oilseeds and spices [6]. Most arable area of the country is currently intensively (cropping intensity was 192 in 2011/12) used for cropping [5, 7]. Besides, about 1.07 million ha prime agricultural land has been converted to nonagricultural usages from 1983 to 2008 [2]. Therefore, availability of land for cropping has been decreasing [7].

Population of this country is likely to be 214.6 million by 2050. Therefore, the country needs to produce additional 14.00 million tonnes of food grains by 2050 [8]. Besides, a large number of studies projected that climate change is likely adversely affected on crops production in the century in Bangladesh $[9,10,11,12,13,14,15]$. On the other hand, yield gaps of rainfed and irrigated rice ranged from 44 to $54 \%$ and $45-61 \%$ of yield potential, respectively across the country [7]. Therefore, increase food production for keeping pace with the growing population is likely a great challenge for the country from the shrinking resources base.

Neoclassical theory indicates that producers are profitmaximizes who take decisions based on expected profitability. Generally, while making production decisions, the farmers consider returns against expected cost [16]. Sometimes it is mentioned that the yield they receive does not cover the cost of production. However, it is very important to identify the profitability and agronomic practice of crops under varying farming situations for selecting best suitable option [16]. Agronomic practice is the key issue which play curtail role for increasing crop productivity [17]. However, we do not find any study to deal with farmers' practice, profitability of rice crops and representation of women in agricultural in particular in the Comilla region. Thus, the present study was undertaken to generate valuable information regarding agronomic practice, performance of rice cultivation in different seasons and roles of women in households in Comilla District. The specific objectives of the study were as follows:

1. Delineate cropping systems, status of varietal adoptions, farmers' crops management practice and level of access to extension services;

2. Assess the profitability of rice grown in the different seasons; and

3. Evaluate roles of women in farming and other decision-making process.

\section{Methodology}

Jalgaon village of Comilla District was purposively selected for this study based on agronomic suitability of growing rice round the year in the village. Farm level data for this study was collected through reconnaissance survey sin December - January 2011/2012. A team included agronomist, socio-economist and field level extension personnel visited the village. The objective of the study was clearly explained to farmers for developing rapport with the villages to generate reliable data. Before, commencing farmers' group discussion (FGD) a transacted walk was carried out to observe the farming systems, cropping systems and other livelihood activities in the village. Thereafter, key informant farmers were identified with the help of farmers and field level extension personnel.

Data was collected through FGD with 15 key informants farmers including large, medium and small was conducted considering crop season 2011-2012. Data related to farmers' perception about land topography, rice variety adoption, cropping pattern, crops management, irrigation system, agricultural mechanization, input use patterns and yields, prices of inputs and outputs were collected. Male respondents were asked about role of women in household and agricultural activities and participation of women in decision making process. The collected data were cleaned before entering into computer. The developed farm budget and other data were validated by the key informant farmers after preliminary analysis in January 2012. Descriptive statistics was used for analyzing the data and tabular and graphical technique was used for presenting the outcome as mean and percentage.

Gross retruns (GR) is the total market value of main and by product of each enterprice. The gross retrun is calculated by multipling the total volume of production of an enterprise by the average farm gate price of that product and by product at harvesting period [18]. Total variable cost of a product was the monetary value of all inputs used for producing that product. In other words, it was estimated by combining all market values of inputs and services used to produce that product [18]. Sum of actual paid-out cost of purchase inputs (seed, fertilizers, pestcides, hired labour, irrigation and thresher) and imputed cost of family supplied inputs (seeds, manure and family supplied inputs) are the total variable cost. Per hectare gross retruns is the sum of value of grain and straw at survey years' market price. Gross margin (GM) of rice was calculated by deducting the total variable costs from gross benfit (GB) for each enterprise

\section{Results and Discussions}

\subsection{Land Topography and Cropping Systems}

The villages were characterized by two broad types of land. These were high land (HL) and medium high land (MHL). MHL was sub-categorized as MHL- $1^{1}$ and MHL- $2^{2}$. About 20 percent land in the village was high land where no standing water remains for longer period during heavy rain or flood. Three-fifth of the land was MHL-1 which is inundated about $0-30 \mathrm{~cm}$ depth during rainy season. Remaining areas (20\%) was MHL-2 which is inundated at about $30-90 \mathrm{~cm}$ depth in the monsoon. Soils of the village were mostly loam and clay loam [5].

Table 1 presents land topography wise cropping in Jalgaon village. T. Aman-Potato-Aus and T. Aman- Winter vegetableAus were the two major cropping patterns of high land. T. Aman-Taro-Taro and T. Aman-Boro-Aus were adopted about 60 percent and 40 percent of medium high Land one, respectively. T. Aman-Boro-Fallow and T. Aman-Boro-Aus

$1 \mathrm{MHL}-1$ which is inundated about $0-30 \mathrm{~cm}$ depth during rainy season 2MHL-2which is inundated about $30-90 \mathrm{~cm}$ depth during rainy season 
were the major two cropping patterns of medium high land $2^{3}$ of the study village. It can be noted that intensity of cropping in the study village was very high. Farmers were growing at least three crops in most of the land within a year (Table 1).

Table 1. Major cropping patterns in the different land topography in Jalgaon.

\begin{tabular}{lll}
\hline Land Topography & Rice based cropping patterns & \% area coverage \\
\hline \multirow{2}{*}{ High Land } & T. Aman-Potato-Aus & 50 \\
& T. Aman-W. Vegetable-Aus & 50 \\
Medium high Land one & T. Aman-Taro-Taro & 60 \\
\multirow{2}{*}{ Medium high Land two } & T. Aman-Boro-Aus & 40 \\
& T. Aman-Boro-Fallow & 50 \\
\hline
\end{tabular}

Note: HL: No flood, MHL1: 0-30 cm, MHL2: 30-90 cm

Source: Field survey, 2011/12.

\subsection{Rice Varietal Adoption}

Table 2 presents adoption rates of major rice varieties in different seasons in Jalgoan village. BRRI dhan28 and BR20 were the major cultivars, covered respectively about 65 percent and 25 percent of total Ausrice area in the village. Similarly, [19] reported that BRRI dhan48, BRRI dhan 28 and BR20 were the major rice varieties, which adoption rates were 15 percent, 27 percent and 16 percent, respectively of total Aus area in the Comilla region in 201617. The drivers of adoption BRRI dhan 28 in Aus season are included shorter span of life, higher yield, tested good to eat, using as seed for following Boro season and lack of availability of seed of newly released varieties at village level.

BRRI dhan32 and BR22 were the dominant T. Aman varieties, jointly covered $90 \%$ of total monsoon rice area in the village. Likewise, reported that BRRI dhan 49, BRRI dhan32 and BR22 were the major T. Aman varieties in Comilla region [19]. The criteria of adoption BRRI dhan 32 are included produces higher grain and straw yield, strong plant and less lodging, tested good to eat etc. BRRI dhan 28 was the dominant Boro season variety which occupied by 60 percent of total Boro rice area in the village. Similarly, BRRI reported that BRRI dhan 28 was top adopted variety in Boro season [19]. Besides, despite some constrains such as not tested good to eat, lower market demand and price, the adoption of hybird was 20 percent of total Boro rice area dueto higher yield (Table 2).

Table 2. Adoption rates of major rice varieties grown in different seasons in Jalgoan.

\begin{tabular}{lll}
\hline Category & Name of variety & Adoption rates \\
\hline Aus & BRRI dhan28 & 65 \\
& BR20 & 25 \\
\multirow{3}{*}{ Aman } & Others & 10 \\
& BRRI dhan32 & 70 \\
& BR22 & 20 \\
\multirow{3}{*}{ Boro } & BRRI dhan39 and 40 & 5 \\
& Others & 5 \\
& BRRI dhan28 & 60 \\
& Hybrid & 20 \\
\hline
\end{tabular}

Source: Field Survey, 2011/12.

\subsection{Crop Management Practice}

\subsubsection{Sowing and Harvesting Time of Crops}

Bangladesh Rice Research Institute (BRRI) recommended optimum time for transplanting T. Aman rice and Aus rice were mid-July to mid-August and mid-March to mid-April, respectively [17]. However, farmers of the study village transplant T. Aman rice from fourth week of July to first week of the September and Aus rice from fourth week of May to first week of June. It was due mainly to harvesting delay of Boro rice because of late transplanting. Mid December to mid-January is the optimum time of transplanting Boro rice [17]. Nevertheless, farmers grow Boro seedlings during mid-December to mid-January and transplant during mid-January to mid-February. Subsequently Aus and T. Aman get delayed (Table 3).

Table 3. Sowing and harvesting time of different crops at study village.

\begin{tabular}{lllll}
\hline Name of crops & Variety & Transplanting time & Harvesting time & Coverage (\%) \\
\hline T. Aman rice & HYV & Fourth week of July to third week of August & Third week of November to Second week of December & 85 \\
T. Aman rice & Local & Third week of August to first week of September & Third to fourth week of December & 15 \\
Aus rice & HYV & Fourth week of May to first week of June & Fourth week of August to first week September & 100 \\
Boro rice & HYV & Mid-January to mid-February & Fourth week of April to third week of May & 100 \\
Taro & HYV & Third to Fourth week of January & Mid-August to first week of September & 100 \\
Potato & HYV & First to third week of December & Mid February to mid-March & 100 \\
\hline
\end{tabular}

Source: Field survey, 2011/12.

\subsubsection{Seed Sources and Rates}

Table 4 shows seed rates and sources of rice seed in the different season in Jalgaon. It Farmers in the village used both the family supplied and purchase seed for rice cultivation in the village. Seed rates of Aus, Aman and Boro season were largely higher than that for BRRI 
recommendation [19]. It may be because of farmers have lack of knowledge on seed rates and germination rates of household seed is low. The reliance on purchase seed was higher for Boro season (80\%) followed T. Aman (60\%) and Aus (55\%) season. Three-fifth of the seed requirement of Boro season was provided by the seed dealer. The dealer purchases seed from BADC and private seed companies. Corresponding figure for Aus and T. Aman seasons were 35 and 40 percent, respectively. However, dependence on household seeds including own stored seed and purchase from other farmers' stored seed were 65,60 and 40 percent in Aus, T. Aman and Boro season, respectively (Table 4).

Table 4. Sources of rice seed grown in the different season in Jalgaon.

\begin{tabular}{llcc}
\hline Items & Aus & T. Aman & Boro \\
\hline Seed $(\mathrm{kg} / \mathrm{ha}):$ & 58 & 51 & 46 \\
& Percent & contribution of & sources \\
Own & 45 & 40 & 20 \\
Purchase from other farmers & 20 & 20 & 20 \\
Purchase from dealer & 35 & 40 & 60 \\
\hline
\end{tabular}

Source: Field Survey 2011/12

\subsubsection{Tillage System}

There were two power tractors in the study village. Farmers of the village fully dependent on those tractors for tillage land over the land 5 to 6 years. Usually two passes are given by tractor for pulverizing the soil for planting rice and non-rice crops. Similarly, reported that farmers mainly relied on two wheel tractor for tillage crop fields in the northwest and south-west regions in Bangladesh [20, 21]. Farmers mentioned that two passes by tractor is adequate for making good health. Per hectare rental change of tractor tillage was BD 4,117for the two passes. Farmers in the village faced poorer access to tractor at pick of the transplanting season of rice which delays the transplanting. The rental change of tractor was high due to higher fuel price. Besides, tractor is unable to reach in the corner of the small plots so that farmers used spade for manually pulverize which increase labour cost.

\subsubsection{Irrigation System}

Earlier (10 years ago) farmers in the village would mainly depended on a DTW for irrigation in the Boro rice. Besides, only a few farmers had own diesel operated pump (STW) for irrigation. Currently, there are eight diesel operated power pump and six electricity operated power pump for irrigation in the village. On the average, about 65 percent and 35 percent of total demand of irrigation were met up by the diesel operated and electricity operated pump, respectively. There was no large variation in the per hectare cost of electricity operated (BDT 12,350/ha) and diesel operated (BDT 14,408/ha) pump. Irrigation distribution system of electric pump was comparatively easy than that of diesel pump. Electric pump owners supply irrigation water to the farmers' field in absence of land owners because they take responsibility to supply necessary irrigation for whole Boro season in exchange of fixed amount of payment.

On an average, 12-14 irrigation was required for Boro rice cultivation in this village. Lack of electricity supply, high price of diesel and difficult to get serial for receiving irrigation water were the major constraints of present irrigation system. Farmers are expecting that with the increase in number of STW the problem of getting water distribution serial will gradually decrease. On an average, 2-3 supplementary irrigation was applied for cultivating T. Aman rice in the study village. Farmers of the village do not have any idea about the irrigation water saving technology like AWD irrigation method.

\subsubsection{Fertilizer Application System}

Availability and application of organic fertilizer has been decreasing due to decrease number of cattle per household overtime in the village. Therefore, farmers in the village are fully dependent on chemical fertilizer for cropping, and the rate of application of the fertilizer has been increasing. It indicates that organic matter of the soil in the village was low because most of the area was occupied by rice crops in three seasons. Farmers applied fertilizers splitting into two top dresses in Aus rice. First top dress included Urea, TSP and MP is applied 12-15 days after transplanting rice. Thereafter, only, urea was applied as second top dress at booting stage of rice. Per hectare fertilizer application rates (Urea, TSP and MP were $165 \mathrm{~kg}, 82 \mathrm{~kg}$ and $62 \mathrm{~kg}$, respectively) (Figure 1) was inconsistent with BRRI recommendation of fertilizer for Aus rice (Urea, TSP and MP were 135, 53 and 83, respectively) (BRRI 2017a). BRRI recommended applying urea as top dress and TSP, MP, Gypsum and Zinc as basal for rice cultivation. Most farmers of the village were not apply gypsum and zinc for growing Aus rice and the rate of Urea, TSP and MP application was higher than that of BRRI recommendation.

Most farmers apply chemical fertilizers splitting into three top dresses in Boro rice in the village. Besides, only a few farmers apply farm yard manure in Boro rice. The first topdressed included Urea, TSP, MP and Gypsum was applied 10-15 days after transplanting while BRRI recommended to apply phosphorus, potash, sulphar and zinc as based. Besides, the second and third top dress of Urea is applied immediately before booting stage and milking stage of the rice crop, respectively. Farmers fertilizer practice (per hectare Urea, TSP, MP and Gypsum application were $268 \mathrm{~kg}, 247 \mathrm{~kg}, 103$ $\mathrm{kg}$ and $206 \mathrm{~kg}$, respectively) is inconsistent with BRRI recommendation (per hectare Urea263-300 kg, TSP90-98 kg, MP150-165 kg, gypsum113 kg and Zincsulphate11 kg) (Figure 2, BRRI, 2017a). 


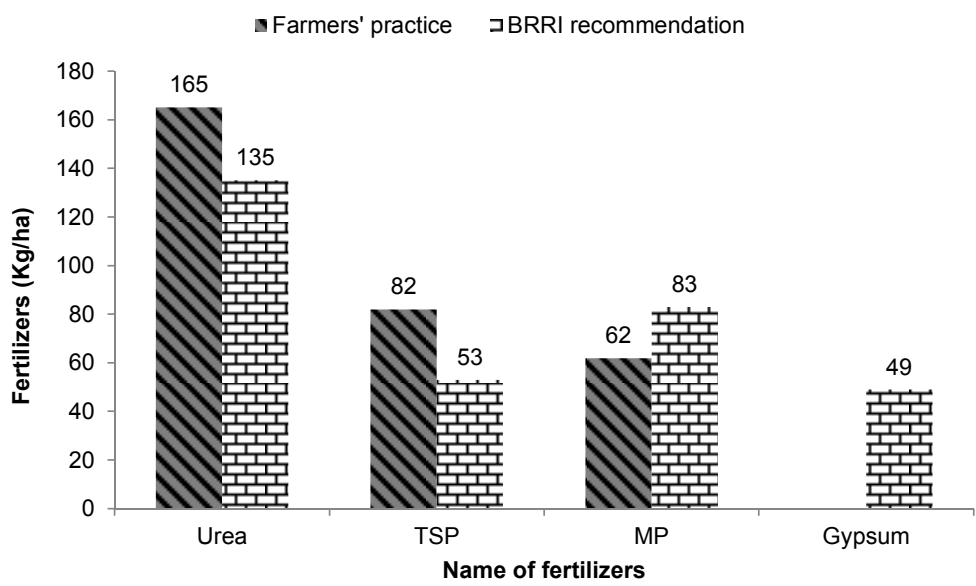

Source: BRRI (2017a)

Figure 1. Farmers' fertilizer practice of Aus rice in Jalgaonvs BRRI recommendation.

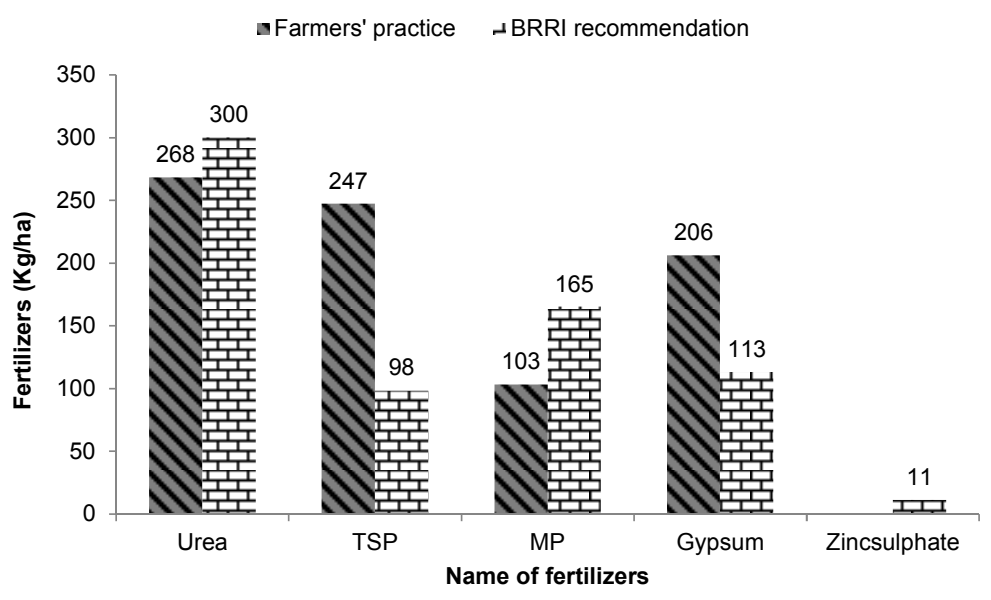

Source: BRRI (2017a).

Figure 2. Farmers' fertilizer practice of Boro rice in Jalgaonvs BRRI recommendation.

Similarly, fertilizer management practice of T. Aman rice (per hectare Urea, TSP, MP and Gypsum were $144 \mathrm{~kg}, 103$ $\mathrm{kg}, 82 \mathrm{~kg}$ and $103 \mathrm{~kg}$, respectively) in the village was inconsistent with recommended practice (Urea $165-195 \mathrm{~kg}$, TSP $60 \mathrm{~kg}$, MP 105-135 kg and gypsum $68 \mathrm{~kg}$ ) (above Figure 3, BRRI 2017a). It was observed from the above
Figure 1, 2 and 3 that farmers of the villagers apply imbalance fertilizers (higher or lower than recommendation and no micronutrient) due to lack of knowledge. Lack of availability of Urea in Boro season and adulteration in fertilizer are recognized as problem.

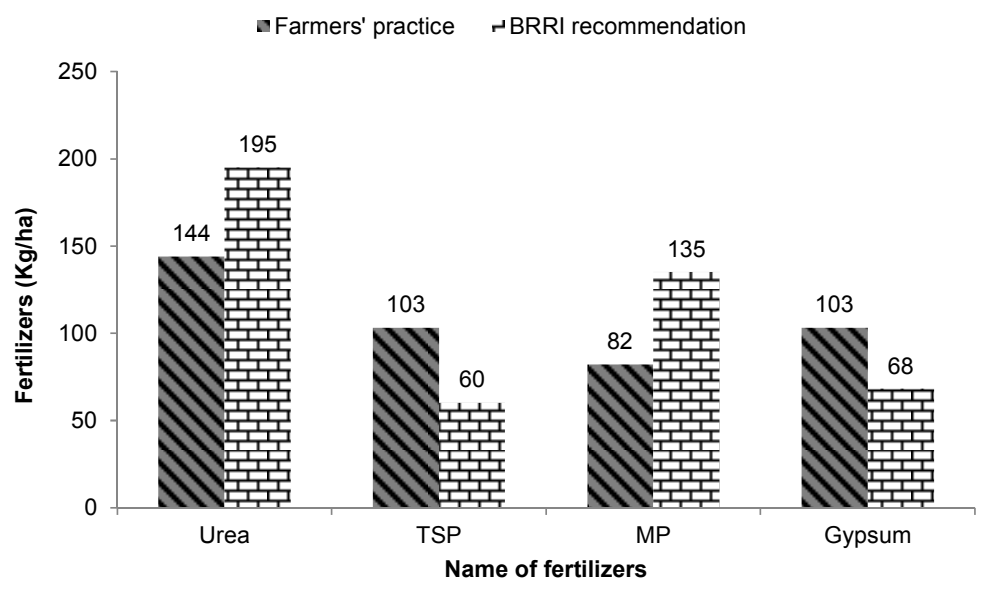

Source: BRRI (2017a).

Figure 3. Farmers' fertilizer practice of T. Aman rice in Jalgaonvs BRRI recommendation. 


\subsubsection{Pest Management and Weed Control}

Farmers in the village mainly rely on chemical method of contorting insects and diseases of crops for the last 20 years. Most farmers apply pesticides in the crops. Besides, some farmers $(20 \%)$ commenced to set perching for controlling insects of rice for the last 2-3 years. Stem Borer and Rice Bug were the major insect and BLB, Sheath Blight, Sheath rot were the major rice diseases in this village. Farmers apply insecticide and pesticide at least three doses in Boro and $\mathrm{T}$. Aman rice and two doses in Aus rice cultivation.

Farmers in the village dependent on manual and chemical methods of controlling weed of rice fields. On the average 23 manual weeding was carried out for controlling weed in the rice fields in the village. Farmers in the commenced applying herbicide in the rice fields for controlling weed since 2007. On the average $60 \%$ of total farmers apply herbicides in the Boro rice. The adoption of the chemical method has been increasing due to less cost.

\subsubsection{Harvesting and Threshing}

Farmers in the village manually harvest rice using family and hired labour in the village. On the other hand, majority ( $85 \%$ of total) of farm household used Paddle thresher for threshing rice. Besides, some farmers $(10 \%$ of total $)$ in particular large farm household used power thresher for threshing rice. In the contrary, marginal farmers ( $5 \%$ of total) were manually threshed rice.

\subsection{Farmers'Access to Extension Services}

Department of Agricultural Extension (DAE) is the pioneer organization works for adoption of new technology at farmer's field. DAE conducted major extension activates included training and demonstration on new technologies, farmers' field days and farmers' field visit. However, farmers in the village had hardly any access to such extension services due may to position of the villages is about $10 \mathrm{~km}$ away from urban centre. Some farmers in the village were observed some extension activates such as variety demonstration outside their village. Farmers in the village said that increased extension supports in particular training and information about the newly developed technologies is critically important for reducing knowledge gap. Besides, demonstrations on newly released varieties and technologies, farmer's field days, farmer's field visit could be helpful for enhancing productivity of crops in the village.

\subsection{Labur Use Pattern and Representation of Inputs in Costs}

Table 5 present sitem wise cost of Aus, Boro and T. Aman rice in Jalgaon. Per hectare human labour requirement for intercultural operation of Ausrice was 136 man-days which incurred BDT 27,200. Besides, per hectare cost of tillage and fertilizers were respectively BDT 4,117 and BDT 6,463. In total cost for Aus rice cultivation was BDT 40,758/ha. Figure 4 shows that human labour represents about $67 \%$ of total variable cost of Aus rice followed by fertilizers (16\%) and tillage (10\%).

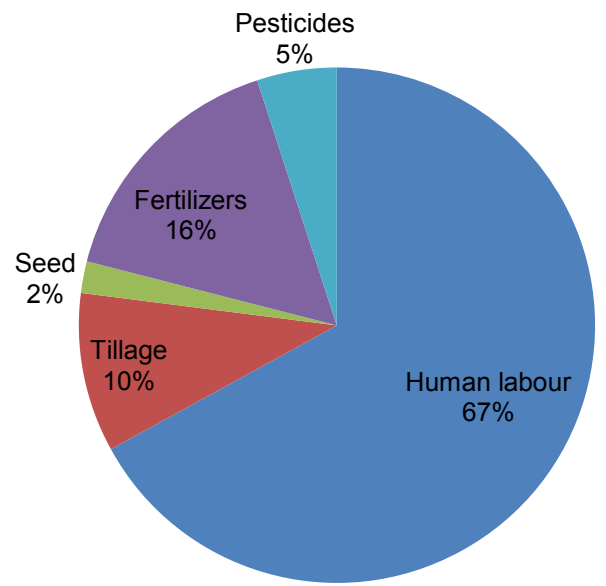

Figure 4. Representation of major inputs in total cost of production T. Aman rice in Jalgaon.

Human labour is intensively employed for different intercultural operations of Boro rice such as land preparations, transplanting, application of fertilizer and pesticides, harvesting, carrying and threshing. Per hectare human labour requirement for intercultural operation of Boro rice was 142 man-days which incurred BDT 31,240. Besides, per hectare cost of tillage, fertilizers and irrigation were respectively BDT 4,117, BDT 15,849 and BDT 14,350. In total cost for Boro rice cultivation was BDT 73,274/ha. Figure 5 shows that human labour represents about $43 \%$ of total variable cost of Boro rice followed by fertilizers $(25 \%)$ and irrigation (20\%).

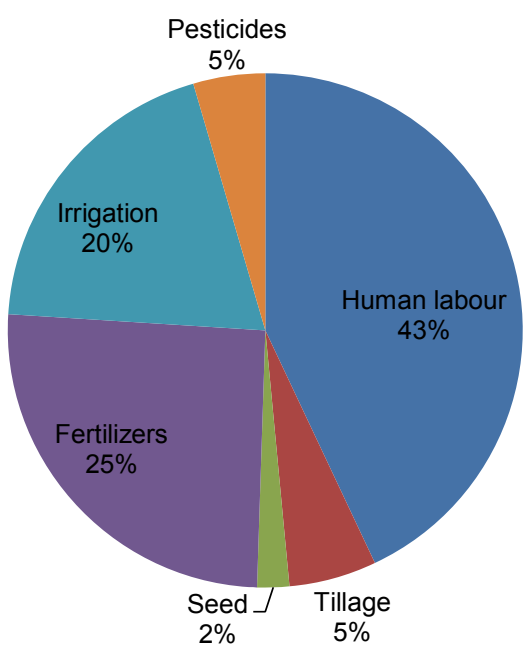

Figure 5. Representation of major inputs in total cost of production T. Aman rice in Jalgaon.

Per hectare human labour requirement for $\mathrm{T}$. Aman rice was 132 man-days which incurred BDT 29,040. Besides, tillage and fertilizers were respectively BDT 4,117 and BDT 8,316 . In total cost for $\mathrm{T}$. Aman rice cultivation was BDT 46,249/ha (Table 5). Human labour represents $63 \%$ of total variable cost of Boro rice followed by fertilizers $(18 \%)$ and 
tillage (9\%) (Figure 6).

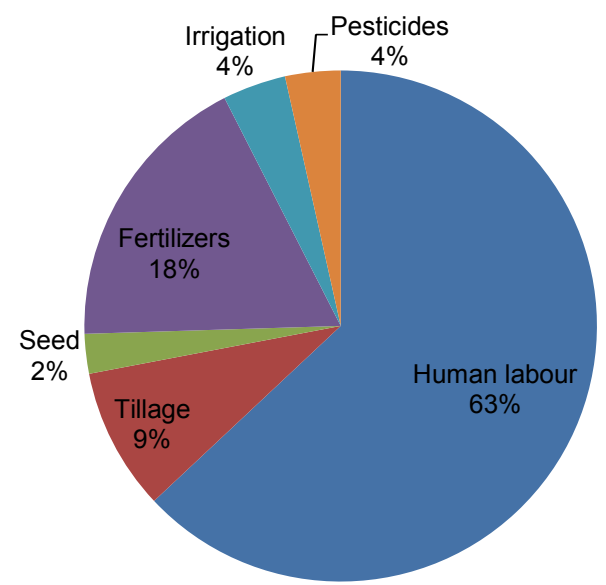

Figure 6. Representation of major inputs in total cost of production T. Aman rice in Jalgaon.

Table 5. Costs, yields and returns of rice grown in different seasons in Jalgaon.

\begin{tabular}{llll}
\hline \multirow{2}{*}{ Items } & \multicolumn{2}{l}{ Rice } & \\
\cline { 2 - 4 } & T. Aman & Boro & Aus \\
\hline Total variable cost (BDT/ha): & 46,116 & 73,275 & 40,758 \\
Human labour & 29,040 & 31,240 & 27,200 \\
Tillage & 4,117 & 4,117 & 4,117 \\
Seed & 1,276 & 1,544 & 920 \\
Fertilizer & 8,316 & 18,731 & 6,463 \\
Irrigation & 1,900 & 14,350 & \\
Pesticides & 1,467 & 3,293 & 2,058 \\
Yield (kg/ha): Grain & 3,293 & 4,940 & 3,088 \\
\hline
\end{tabular}

-Boro $\mathbf{s}$ T. Aman $\approx$ Aus

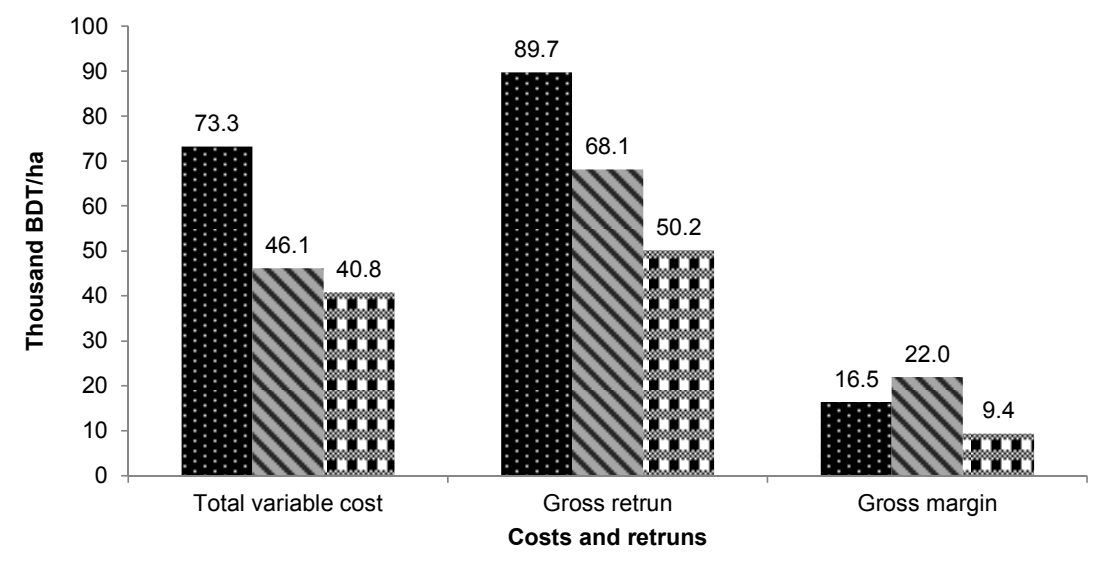

Figure 7. Comparative costs and returns of Aus, T. Aman and Boro rice in Jalgaon.

\subsection{Women's Roles in the Households}

The survey revealed that participation of women in the intercultural activities (e.g., land preparation, tillage, sowing and transplanting of crops, weeding, irrigation application and harvesting and carrying) was a few. Table 6 shows participation of male, female and children in farming and other household activities in Jalgoan. Women in the village did not participate in land preparation, tillage, transplanting crops and irrigation application in the village. A few percent of weeding $(10 \%)$, harvesting $(10 \%)$ and carrying activities

\begin{tabular}{llll}
\hline \multirow{2}{*}{ Items } & Rice & & \\
\cline { 2 - 4 } & T. Aman & Boro & Aus \\
\hline Straw & 3,705 & 3,293 & - \\
Gross returns (BDT/ha): & 68,131 & 89,743 & 50,172 \\
Value of grain & 62,573 & 86,450 & 50,172 \\
Value of straw & 5,558 & 3,293 & - \\
Gross margin (BDT/ha) & 22,015 & 16,468 & 9,414 \\
\hline
\end{tabular}

\subsection{Costs, Yields and Returns}

Per hectare cost of Boro rice was largely than that of $\mathrm{T}$. Aman and Aus rice. It is because of Boro rice more inputs intensive and it has a large addition cost for irrigation than rainfed T. Aman and Aus rice. Per hectare yield of Boro rice was higher (4.94 t/ha) followed by T. Aman (3.29 t/ha) and Aus (3.08 t/ha) because of better cropping environment and farmers apply more fertilizers better genotypes in Boro season (Table 5). Similarly, reported that Boro rice gave higher yield than that of T. Aman and Aus rice (BRRI, 2017a). The performance of rice under farmers practice in study village was largely lower than potential performance of modern Boro, Aus and T. Aman varieties (BRRI 2017a). It is likely due three rice based (rice-rice-rice) cropping pattern and large gap between farmers practice and recommendation management. Not surprisingly, per hectare gross benefit of Boro rice was higher followed by T. Aman and Aus rice due to higher yield. However, gross income per hectare of T. Aman was higher than that of even Boro rice due to higher paddy price and low cost of production. These results are consistent with the results reported by BRRI (2017a) (Figure 7). were performed by the women. However, women' had key contribution in post-harvest activities such as threshing $(85 \%)$ and winnowing \& drying (95\%). Besides crop farming, women kept significant contribution in livestock rearing $(80 \%)$, child care $(70 \%)$ and cooking $(100 \%)$ along with kitchen work (Table 6). Similarly, reported that participation of women in the cropping activities in the fields was low but they have significant contribution in post-harvest processing of crops, rearing livestock and other household's activities in the adjacent District Noakhalia [22, 23]. In contrast, in a study [24] it is reported that participation of 
women in farming is very high in the coastal District Khulna.

Table 6. Participation of male, female and children in farming and household activities in Jalgaon.

\begin{tabular}{llll}
\hline Activities & Female (\%) & Male (\%) & Children (\%) \\
\hline Land preparation/tillage & - & 100 & - \\
Sowing/transplanting & - & 100 & - \\
Weeding & 10 & 90 & - \\
Irrigation & - & 100 & - \\
Harvesting and carrying rice & 10 & 90 & - \\
Threshing rice & 85 & 15 & - \\
Harvesting Rabi crops & 45 & 45 & 10 \\
Winnowing/drying & 95 & 5 & - \\
Livestock rearing & 80 & 10 & 10 \\
Cooking, kitchen work & 100 & - & - \\
Child care & 70 & 10 & 20 \\
\hline
\end{tabular}

Table 7 presents representation of women in decision making about farming and other household affairs in Jalgaon. Women's contributions in decision making about farming in particular selection of crops and crops cultivars to be grown, sowing, planting and harvesting dates of crops and hiring and selling labour was a few. However, women had equal roles as their male counterpart in decision making of buying and selling of properties, livestock, participation in borrowing groups and marriage of children (Table 7).

Table 7. Women's roles in decision-making about cropping and other household affairs in Jalgaon.

\begin{tabular}{ll}
\hline Items & $\begin{array}{l}\text { Women' } \\
\text { contribution (\%) }\end{array}$ \\
\hline Selection ofrice and non-rice crops and crops cultivars & 10 \\
Crops sowing, transplanting and harvesting dates & 10 \\
Hiringlabour & 15 \\
Buying and selling of rice and non-rice crops & \\
Livestock keeping, buying and selling & 60 \\
Buying and selling of property & 50 \\
Marriage of children & 50 \\
Participation in institutional groups and borrowing & 50 \\
\hline
\end{tabular}

\section{Conclusion}

Rice-rice-rice is the dominant cropping patterns in the village. Farmers' practice of rice farming is highly inconsistent with recommendation practice in terms of time of establishing crops, seeds and fertilizers rates and pesticides. Farmers used higher seeds because of lower germination rates of household seeds (owned stored and purchase from neighboring farmers). However, apply lower doses of fertilizers due to lack of knowledge and money. Boro rice gave higher yield (4.94 t/ha) followed by T. Aman (3.29 t/ha) and Aus (3.09 t/ha) because of better management and genotypes. However, T. Aman gave higher gross margin (BDT 22,015/ha) followed by Boro (BDT 16,468/ha) and Aus (BDT 9,414/ha) rice because of good price and low production cost. Women are intensively participated in post-harvest processing of crops and other household activates as well as households decision other than farming. In short, rice production is profitable in the three seasons at survey year's price. However, poorer access to extension service, good quality seed, phosphorous fertilizers, pesticides and power supply during Boro season were identified as barrier to achieve potential performance of rice cultivars and expected level of returns. It can be noted that increased access to extension services (e.g., training, demonstration, farmers' field day and farmers' field visit by field staff) and ensured access to quality seeds, fertilizers and price of rice may enhance farm level productivity and profitability of rice production.

\section{References}

[1] BBS 2011, 'Bangladesh Population and Housing Census 2011, Bangladesh Bureau of Statistics, Ministry of Planning, Bangladesh', Government of the People's Republic of Bangladesh. Dhaka, Bangladesh.

[2] BBS 2016a, Statistical Year Book of Bangladesh 2016, Bangladesh Bureau of Statistics, Ministry of Planning, Bangladesh, Government of the People's Republic of Bangladesh. Dhaka, Bangladesh.

[3] BER 2007, 'Bangladesh Economic Review (BER) 2007', Ministry of Finance, Government of the People's Republic of Bangladesh, Dhaka, Bangladesh.

[4] BER 2017, 'Bangladesh Economic Review (BER) 2017', Ministry of Finance, Government of the People's Republic of Bangladesh, Dhaka, Bangladesh.

[5] BBS 2016b, 'Year Book of Agricultural Statistical Bangladesh 2016', Bangladesh Bureau of Statistics, Ministry ofPlanning, Bangladesh, Government of the People's Republic of Bangladesh. Dhaka, Bangladesh.

[6] Mainuddin, K, Rahman, A, Islam, N \& Quasem, S 2011, 'Planning and costing agriculture's adaptation to climate change in the salinity-prone cropping system of Bangladesh', International Institute for Environment and Development (IIED), London, UK.

[7] Timsina, J, Wolf, J, Guilpart, N, van Bussel, LGJ, Grassini, P, van Wart, J, Hossain, A, Rashid, H, Islam, S \& van Ittersum, MK 2016, 'Can Bangladesh produce enough cereals to meet future demand?', Agricultural Systems (In Press).

[8] Hussain, SG 2011, 'Assessing Impacts of Climate Change on Cereal Production and Food Security in Bangladesh', in R Lal, AHMM Rahman, MVK Sivakumar, KR Islam \& SMA Faiz (eds), Climate Change and Food Security in South Asia, Springer, Netherlands, pp. 459-476.

[9] Yu, WH, Alam, M, Hassan, A, Khan, AS, Ruane, AC, Rosenzweig, C, Major, DC \&Thurlow, J 2010, Climate Change Risks and Food Security in Bangladesh, Earthscan, Washington, DC, USA.

[10] Thurlow, J, Dorosh, P \& Yu, W 2012, 'A Stochastic Simulation Approach to Estimating the Economic Impacts of Climate Change in Bangladesh', Review of Development Economics, 169 (3), pp. 412-428.

[11] Ruane, AC, Major, DC, Yu, WH, Alam, M, Hussain, SG, Khan, AS, Hassan, A, Hossain, BMTA, Goldberg, R, Horton, RM \& Rosenzweig, C 2013, 'Multi-factor impact analysis of agricultural production in Bangladesh with climate change', Global Environmental Change, 23 (1), pp. 338-350. 
[12] WB 2013, Turn down the heat: climate extremes, regional impacts, and the case for resilience, 1464800561, The World Bank (WB), Washington, DC, USA

[13] IPCC 2014a, 'Climate Change 2014: Impacts, Adaptation, and Vulnerability', Part A: Global and Sectoral Aspects. Contribution of Working Group II to the Fifth Assessment Report of the Intergovernmental Panel on Climate Change (IPCC), Cambridge University Press, Cambridge, UK.

[14] Kabir, MJ 2016, 'The Sustainability of Rice-Based Cropping Systems in Coastal Bangladesh: Bio-Economic Analysis of Current and Future Climate Scenarios', PhD thesis, The University of Queensland (UQ).

[15] Kabir, MJ, Gaydon, DS, Cramb, R, \& Roth, C 2017a, 'Bioeconomic evaluation of cropping systems for saline coastal Bangladesh: I. Simulation under historical and future environments', Submitted and in-review with Agricultural Systems.

[16] Dillon, JL and Hardaker, JB 1993, 'Farm Management Research for Small Farmer Development', vol. 6, Food and Agriculture Organization of the United Nations (FAO), Rome, Italy.

[17] BRRI 2017b, 'Adunik Dhaner Chash (Modern Rice
Cultivation)' (in bangla language), 19edn, Bangladesh Rice Research Institute (BRRI), Gazipur, Bangladesh.

[18] Dillon, JL and Hardaker, JB 1980, 'Farm Management Research for Small Farmer Development', vol. 6, Food and Agriculture Organization of the United Nations (FAO), Rome,, Italy.

[19] BRRI 2017a, 'Annual Report 2017', Bangladesh Rice Research Institute (BRRI), Gazipur, Bangladesh.

[20] Kabir, MJ, Cramb, R, Alauddin, M \& Roth, C 2016, 'Farming adaptation to environmental change in coastal Bangladesh: shrimp culture versus crop diversification', Environment, Development and Sustainability, 18 (4), pp. 1195-1216.

[21] Kabir, MJ, Alauddin, M and Crimp, S 2017b, 'Farm-level adaptation to climate change in Western Bangladesh: An analysis of adaptation dynamics, profitability and risks', Land Use Policy, 64, pp. 212-224.

[22] BRRI 2016, 'Annual Report 2016', Bangladesh Rice Research Institute (BRRI), Gazipur, Bangladesh.

[23] Kabir, MJ, Cramb, R, Alauddin, M, Roth, C and Crimp, S $2017 \mathrm{c}$,'Farmers' perceptions of and responses to environmental change in southwest coastal Bangladesh', Asia Pacific Viewpoint, 58 (3), pp. 362-378. 